\title{
Use of Sugammadex in a Patient With Myotonic Dystrophy
}

\author{
Samira Ahmed ${ }^{\mathrm{a}}$, Aymen Naguiba, b, Dmitry Tumin ${ }^{\mathrm{a}, \mathrm{c}}$, \\ Joseph D. Tobias ${ }^{a, b, d}$
}

\begin{abstract}
One of the challenges during the perioperative care of patients with myotonic dystrophy is the reversal of neuromuscular blocking agents. Agents that inhibit acetylcholinesterase, such as neostigmine, may precipitate myotonia, and are therefore relatively contraindicated. Sugammadex is a novel pharmacologic agent, which encapsulates rocuronium or vecuronium, thereby reversing their effect. We report anecdotal experience with the use of sugammadex to reverse neuromuscular blockade in a patient with myotonic dystrophy. Concerns with the reversal of neuromuscular blockade in patients with myotonic dystrophy are presented, previous reports of the use of sugammadex in similar clinical scenarios are reviewed, and its advantages are discussed.
\end{abstract}

Keywords: Sugammadex; Myotonic dystrophy

\section{Introduction}

Myotonic dystrophy (DM) is an autosomal dominant inherited disorder of the sarcolemma with an incidence of $3-5 / 100,000$ that was first reported by Steinert in 1909 [1]. As the primary defect lies in the muscle membrane (sarcolemma) distal to the neuromuscular junction, abnormal responses to both depolarizing and non-depolarizing neuromuscular blocking agents may impact perioperative care $[2,3]$. Reversal of neuromuscular blockade with agents that inhibit acetylcholinesterase (neostigmine) may precipitate myotonia, and is therefore relatively contraindicated $[4,5]$.

Sugammadex Bridion $^{\circledR}$, Merck \& Co., Whithouse Stations, NJ) is a novel pharmacologic agent, which was approved for clinical use in December 2015 by the United States Food \&

Manuscript submitted December 5, 2017, accepted December 12, 2017

aDepartment of Anesthesiology \& Pain Medicine, Nationwide Children's Hospital, Columbus, OH, USA

bepartment of Anesthesiology \& Pain Medicine, The Ohio State University College of Medicine, Columbus, OH, USA

'Department of Pediatrics, The Ohio State University College of Medicine, Columbus, OH, USA

${ }^{\mathrm{d} C}$ Corresponding Author: Joseph D. Tobias, Department of Anesthesiology \& Pain Medicine, Nationwide Children's Hospital, 700 Children's Drive, Columbus, OH 43205, USA. Email: Joseph.Tobias@Nationwidechildrens.org

doi: https://doi.org/10.14740/cr650w
Drug Administration (FDA). It reverses neuromuscular blockade with a mechanism that differs completely from acetylcholinesterase inhibitors, by encapsulating rocuronium or vecuronium. Thereby, sugammadex may provide complete recovery even when there is significant residual neuromuscular blockade [6]. We report anecdotal experience with the use of sugammadex to reverse neuromuscular blockade in a patient with DM. Perioperative concerns regarding the use and reversal of neuromuscular blockade in patients with DM are presented, previous reports regarding the use of sugammadex in similar clinical scenarios are reviewed, and its potential advantages in this clinical scenario are discussed.

\section{Case Report}

Institutional Board Review is not required at Nationwide Children's Hospital (Columbus, $\mathrm{OH}$ ) for the presentation of a single case report.

\section{First anesthetic encounter}

The patient was a 25 -year-old, $51.6 \mathrm{~kg}$ male, who was admitted for cardiothoracic surgery (Bentall procedure including composite graft replacement of the aortic valve, aortic root and ascending aorta, with re-implantation of the coronary arteries into the graft). He had a history of progressive aortic valve insufficiency due to bicuspid aortic valve and ascending aortic aneurysm. He was known to have DM type 1 (Steinert disease). Clinical examination revealed symmetrical facial weakness, ptosis with temporal balding and wasting. There was upper and lower limb muscle weakness. His family history was positive for other members with DM. Preoperative electrocardiogram (ECG) showed a sinus rhythm with a heart rate of 54 beats per minute (bpm), an intraventricular conduction delay, left ventricular hypertrophy, and early repolarization. Echocardiogram showed an abnormal bicuspid aortic valve, moderate aortic stenosis and regurgitation, severe aortic root and ascending aorta dilation, moderate-to-severe left ventricular enlargement, and qualitatively normal left ventricular systolic function. Laboratory evaluations, including complete blood count, electrolytes, renal function, and coagulation profile, were within normal limits. His current medications included cholecalciferol. The patient was held nil per os (NPO) for $6 \mathrm{~h}$ and transported to the operating room where American Society of Anesthesiologists' (ASA) monitors were placed. A peripheral intravenous catheter was placed and a 
Table 1. Previous Reports of Sugammadex Use in Patients With Myotonic Dystrophy

\begin{tabular}{|c|c|c|}
\hline Author and reference & Patient demographics & Outcome and anesthetic care \\
\hline Pickard et al [10] & $\begin{array}{l}\text { A 14-month-old child } \\
\text { with DM for endoscopic } \\
\text { gastrostomy tube } \\
\text { placement, orchidopexy, } \\
\text { and division of tongue tie }\end{array}$ & $\begin{array}{l}\text { General anesthesia with sevoflurane and fentanyl. Rocuronium }(0.8 \mathrm{mg} / \mathrm{kg}) \text { to facilitate } \\
\text { endotracheal intubation. Fifty-seven minutes after rocuronium, no response of the TOF. } \\
\text { Sugammadex }(5 \mathrm{mg} / \mathrm{kg} \text { ) resulted in a TOF ratio of } 96 \% \text {. However, this fell to } 60 \% \text { and } \\
\text { a second dose of sugammadex ( } 5 \mathrm{mg} / \mathrm{kg} \text { ) was administered. The TOF ratio was } 86 \% \\
\text { and remained stable. The patient's trachea was extubated. }\end{array}$ \\
\hline Stourac et al [11] & $\begin{array}{l}\text { A } 37 \text {-year-old woman with } \\
\text { DM for cesarean section }\end{array}$ & $\begin{array}{l}\text { Anesthetic induction and endotracheal intubation with propofol }(2 \mathrm{mg} / \mathrm{kg}) \text { and } \\
\text { rocuronium }(1 \mathrm{mg} / \mathrm{kg}) \text {. At the completion of the procedure }(50 \mathrm{~min}) \text {, there were no } \\
\text { twitches. Sugammadex }(2 \mathrm{mg} / \mathrm{kg}) \text { resulted in a TOF of } 0.9 \mathrm{in} 2 \mathrm{~min} \text { and the patient's } \\
\text { trachea was extubated. }\end{array}$ \\
\hline Petrovski et al [12] & $\begin{array}{l}\text { A } 43 \text {-year-old woman } \\
\text { with DM for cystoscopy } \\
\text { and colonoscopy }\end{array}$ & $\begin{array}{l}\text { Anesthesia was induced with sevoflurane in oxygen supplemented with propofol. } \\
\text { Endotracheal intubation was facilitated by rocuronium }(50 \mathrm{mg}) \text {. Although there } \\
\text { was no residual neuromuscular blockade on the TOF, sugammadex }(200 \mathrm{mg}) \text { was } \\
\text { administered to ensure complete reversal. Her trachea was extubated without problems. }\end{array}$ \\
\hline Matsuki et al [14] & $\begin{array}{l}\text { A } 24 \text {-year-old woman } \\
\text { with DM for laparoscopic } \\
\text { ovarian cystectomy }\end{array}$ & $\begin{array}{l}\text { Anesthesia was induced and maintained with propofol and remifentanil. Repetitive } \\
\text { TOF stimulation was applied followed by rocuronium }(0.3 \mathrm{mg} / \mathrm{kg}) \text { for endotracheal } \\
\text { intubation. At the completion of surgery, T } 2 \text { of the TOF was present and sugammadex } \\
(2 \mathrm{mg} / \mathrm{kg}) \text { was administered. Within } 2 \mathrm{~min} \text {, the TOF ratio was } 0.9 \text {. The patient's trachea } \\
\text { was extubated. }\end{array}$ \\
\hline Gurunathan et al [15] & $\begin{array}{l}\text { A } 60 \text {-year-old, } 70 \\
\text { kg man with DM for } \\
\text { elective laparoscopic } \\
\text { cholecystectomy }\end{array}$ & $\begin{array}{l}\text { Anesthesia was induced with midazolam and propofol. Endotracheal intubation was } \\
\text { facilitated by rocuronium }(50 \mathrm{mg}) \text {. After } 45 \mathrm{~min} \text {, there were no twitches on the TOF. } \\
\text { Sugammadex ( } 200 \mathrm{mg} \text { ) was administered and within } 30 \mathrm{~s} \text {, there were four twitches } \\
\text { without fade and the patient's trachea was. }\end{array}$ \\
\hline Mavridou et al [16] & $\begin{array}{l}\text { A } 40 \text {-year-old, } 74 \\
\mathrm{~kg} \text { woman with DM } \\
\text { for laparoscopic } \\
\text { cholecystectomy and } \\
\text { ovarian cystectomy }\end{array}$ & $\begin{array}{l}\text { Anesthesia was induced with propofol }(2 \mathrm{mg} / \mathrm{kg}) \text { and rocuronium }(30 \mathrm{mg}) \text {. TOF was } \\
\text { applied and endotracheal intubation was facilitated by rocuronium }(30 \mathrm{mg}) \text {. Anesthesia } \\
\text { was maintained with propofol and remifentanil. After } 90 \mathrm{~min} \text {, there was a reappearance } \\
\text { of T2 on TOF. Sugammadex }(2 \mathrm{mg} / \mathrm{kg}) \text { was administered and within } 2 \mathrm{~min} \text {, the TOF } \\
\text { was } 1 \text {. Opioid reversal was necessary, but the trachea was successfully extubated. }\end{array}$ \\
\hline
\end{tabular}

DM: myotonic dystrophy; TIVA: total intravenous anesthesia; TOF: train of four.

rapid sequence induction (RSI) with endotracheal intubation was carried out with the following medications: midazolam (2 mg), fentanyl $(100 \mu \mathrm{g})$, etomidate $(10 \mathrm{mg})$, propofol $(30$ $\mathrm{mg})$, rocuronium $(50 \mathrm{mg})$, and lidocaine $(60 \mathrm{mg})$. Endotracheal intubation proceeded without difficulty. Maintenance anesthesia was provided with desflurane, dexmedetomidine $(0.5 \mu \mathrm{g} / \mathrm{kg} / \mathrm{h})$, and intravenous fentanyl. Bilateral paravertebral blocks (total of $40 \mathrm{~mL}$ of $0.2 \%$ ropivacaine) were placed using ultrasound guidance for postoperative analgesia. A central venous catheter and a radial arterial line were placed. Cardiopulmonary bypass (CPB) time was $3 \mathrm{~h} 10 \mathrm{~min}$ with an aortic cross-clamp time of approximately $2 \mathrm{~h}$. The patient weaned from CPB with epinephrine and milrinone infusions. The patient received a total of $110 \mathrm{mg}$ of rocuronium during the surgery. After completion of the procedure, neuromuscular blockade was reversed with sugammadex ( $4 \mathrm{mg} / \mathrm{kg})$. After return of appropriate strength and spontaneous ventilation, his trachea was extubated when he was awake in the operating room. He was transferred to the cardiothoracic intensive care unit in stable condition and his postoperative course was unremarkable.

\section{Second anesthetic encounter}

Five weeks later, the patient returned for transesophageal echocardiography (TEE) and cardioversion due to atrial flutter with depressed myocardial function. His current medications included coumadin (2 mg PO every evening), enalapril $5 \mathrm{mg}$ BID, and cholecalciferol. He was held NPO for $6 \mathrm{~h}$ and was transported to the cardiac procedure room where routine ASA monitors were placed. RSI with endotracheal intubation was performed with the following medications: etomidate $(16 \mathrm{mg})$, fentanyl $(25 \mu \mathrm{g})$, and rocuronium $(50 \mathrm{mg})$. His trachea was intubated without difficulty and maintenance anesthesia provided with desflurane. TEE was performed, followed by electrical cardioversion, which resulted in a return to normal sinus rhythm. Forty-three minutes after the single dose of rocuronium, sugammadex ( $4 \mathrm{mg} / \mathrm{kg})$ was administered. Within $10 \mathrm{~min}$, he had return of baseline neuromuscular function and when 
awake, his trachea was extubated. His postoperative course was unremarkable.

\section{Discussion}

Increased perioperative morbidity and mortality in patients with DM may be related to respiratory failure, upper airway obstruction with sleep disordered breathing, cardiac failure or arrhythmias, and aspiration related to gastrointestinal involvement. Furthermore, patients with DM have been shown to have an increased risk for perioperative respiratory insufficiency and failure, related to an increased sensitivity to opioids, benzodiazepines, and the inhalational anesthetic agents. Given the associated muscle weakness and the potential for exacerbation of myotonia, the choice of neuromuscular blocking agent and agents for reversal may significantly impact the perioperative course. The Myotonic Dystrophy Foundation has provided recommendations for the anesthetic management of patients with DM, including the avoidance of succinylcholine and neostigmine.

With the potential for the aspiration of stomach contents, RSI may be indicated, necessitating the use of an agent that provides the rapid onset of neuromuscular blockade [7]. As noted above, succinylcholine is contraindicated given its potential to exacerbate myotonia causing rigidity. This necessitates the use of non-depolarizing agents, such as rocuronium, which have significantly longer duration of action. Furthermore, baseline muscle weakness potentially leads to increased sensitivity to non-depolarizing agents, with a higher incidence of prolonged residual neuromuscular blockade [4, 8, 9]. Prolonged or residual neuromuscular blockade affects upper airway control and respiratory function, thereby impacting the postoperative course. These issues are compounded by the fact that reversal with acetylcholinesterase inhibitors can potentiate myotonia and is therefore contraindicated. As such, postoperative endotracheal intubation and mechanical ventilation may be required.

Given its novel mechanism of action, sugammadex provides a means of reversing neuromuscular blockade in patients with DM without exacerbating myotonia. Its mechanism of action allows for complete reversal of neuromuscular blockade with limited change of residual motor weakness [6]. Following both procedures in our patient, sugammadex $(4 \mathrm{mg} / \mathrm{kg})$ effectively reversed neuromuscular blockade and allowed for early tracheal extubation. Additional anecdotal reports from the literature have demonstrated the potential utility of sugammadex in similar clinical scenarios in patients with DM (Table 1) $[10-16]$.

These case reports, along with the experience in the two anesthetics for our patient, demonstrate the utility of sugammadex in this challenging patient population. In these scenarios, including those with a neuromuscular or myopathic disease process, sugammadex appears promising for reversal of neuromuscular blockade. Its unique mechanism of action offers several potential benefits over cholinesterase inhibitors such as neostigmine. It may be useful in scenarios such as DM where cholinesterase inhibitors are contraindicated, when there is intense residual neuromuscular blockade, or in patients with underlying weakness or hypotonia when residual neuromuscular blockade may be particularly detrimental.

\section{References}

1. Steinert H. Myopathologische beitrage ueber das klinicheund anatomische bild des muskel-schwunds der myotoniker. Deutsche Zeitschrift Newenheilk. 1909;37:5859.

2. Subramaniam A, Grauer R, Beilby D, Tiruvoipati R. Anesthetic management of a myotonic dystrophy patient with paraganglionoma. J Clin Anesth. 2016;34:21-28.

3. Tobias JD. Anesthetic management of the child with myotonic dystrophy: epidural anesthesia as an alternative to general anesthesia. Paediatr Anaesth. 1995;5:335-338.

4. Russell SH, Hirsch NP. Anaesthesia and myotonia. Br J Anaesth. 1994;72(2):210-216.

5. Buzello W, Krieg N, Schlickewei A. Hazards of neostigmine in patients with neuromuscular disorders. Report of two cases. Br J Anaesth. 1982;54(5):529-534.

6. Tobias JD. Current evidence for the use of sugammadex in children. Paediatr Anaesth. 2017;27(2):118-125.

7. Anderson BJ, Brown TC. Congenital myotonic dystrophy in children - a review of ten years' experience. Anaesth Intensive Care. 1989;17(3):320-324.

8. Thiel RE. The myotonic response to suxamethonium. $\mathrm{Br}$ J Anaesth. 1967;39(10):815-821.

9. Diefenbach C, Lynch J, Abel M, Buzello W. Vecuronium for muscle relaxation in patients with dystrophia myotonica. Anesth Analg. 1993;76(4):872-874.

10. Pickard A, Lobo C, Stoddart PA. The effect of rocuronium and sugammadex on neuromuscular blockade in a child with congenital myotonic dystrophy type 1 . Paediatr Anaesth. 2013;23(9):871-873.

11. Stourac P, Krikava I, Seidlova J, Strazevska E, Huser M, Hruban L, Janku P, et al. Sugammadex in a parturient with myotonic dystrophy. Br J Anaesth. 2013;110(4):657-658.

12. Petrovski J. The use of sugammadex to reverse rocuronium in a patient with myotonic dystrophy. Anaesth Intensive Care. 2011;39(3):505-506.

13. Baumgartner P. Rocuronium and sugammadex in myotonic dystrophy. Anaesth Intensive Care. 2010;38(5):959960 .

14. Masaoka Y. [Impairment of odor recognition in myotonic dystrophy type 1]. Brain Nerve. 2016;68(2):145-150.

15. Gurunathan U, Duncan G. The successful use of sugammadex and uneventful recovery from general anaesthesia in a patient with myotonic dystrophy. Indian J Anaesth. 2015;59(5):325-326.

16. Mavridou P, Dimitriou V, Margaritis A, Manataki A. Anesthesia for laparoscopic surgery in a patient with myotonic dystrophy (Steinert's disease): beneficial use of sugammadex, but incorrect use of pethidine: a case report. Acta Anaesthesiol Belg. 2011;62(2):101-104. 